\title{
Are Diverse Factors Proxies for Architectural Influences? A Case for Architecture in the Aetiology of Schizophrenia.
}

\author{
Jan A. Golembiewski ${ }^{1}$ \\ 1. Creative Industries, Queensland University of Technology
}

$\square$ Corresponding author: Jan A. Golembiewski, greenmanarch@gmail.com

Disclosures can be found in Additional Information at the end of the article

\section{Abstract}

Introduction: The last half-century of epidemiological enquiry into schizophrenia can be characterized by the search for neurological imbalances and lesions for genetic factors. The growing consensus is that these directions have failed, and there is now a growing interest in psychosocial and developmental models. Another area of recent interest is in epigenetics - the multiplication of genetic influences by environmental factors.

Methods: This integrative review comparatively maps current psychosocial, developmental and epigenetic models for schizophrenia epidemiology to identify crossover and theoretical gaps.

Results: In the flood of data that is being produced around the schizophrenia epidemiology, one of the most consistent findings is that schizophrenia is an urban syndrome. Once demographic factors have been discounted, between one-quarter and one-third of all incidence is repeatedly traced back to urbanicity - potentially threatening more established models, such as the psychosocial, genetic and developmental hypotheses.

Conclusions: Close analysis demonstrates how current models for schizophrenia epidemiology appear to miss the mark. Furthermore, the built environment appears to be an inextricable factor in all current models and indeed may be a valid epidemiological factor on its own. The reason the built environment hasn't already become a de rigueur area of epidemiological research is possibly trivial - it just doesn't attract enough science, and lacks a hero to promote it alongside other hypotheses.

Received 01/25/2013 Review began 01/28/2013 Published 03/18/2013

\section{C) Copyright 2013}

Golembiewski. This is an open access article distributed under the terms of the Creative Commons Attribution License CC-BY 3.0., which permits unrestricted use, distribution, and reproduction in any medium, provided the original author and source are credited.
Categories: Psychiatry, Psychology, Epidemiology/Public Health

Keywords: schizophrenia, epidemiology, architecture, urban health, social factors, epigenetics, built environment, vitamin $d$, salutogenics

\section{Introduction And Background}

Ever since John Snow successfully combined statistics and mapping to identify the Broad Street pump as the source of London's cholera epidemic of 1854, attempts have been made to do the same for other illnesses. Like the Broad St. Pump study, the research of Faris and Dunham into the incidence of 'insanity' in Chicago also found a locus of concentration - the inner city slum area [1]; but neither pump nor pathogen was found. Instead, the authors pointed to various 'breeder' factors: race, migration status, poverty, and access to sunlight. To make sure this was 


\section{Cureus}

not a case of the 'cum hoc ergo propter hoc' fallacy (for confusing correlation with cause), Faris and Dunham gave evidence to counter the 'drift effect' caused by downward social mobility in those with mental illness. They found that parents of the 'insane' are equally likely to inhabit the slums. The possibility that upward (unaffected) social mobility out of these areas may increase concentrations was not raised for many years [2].

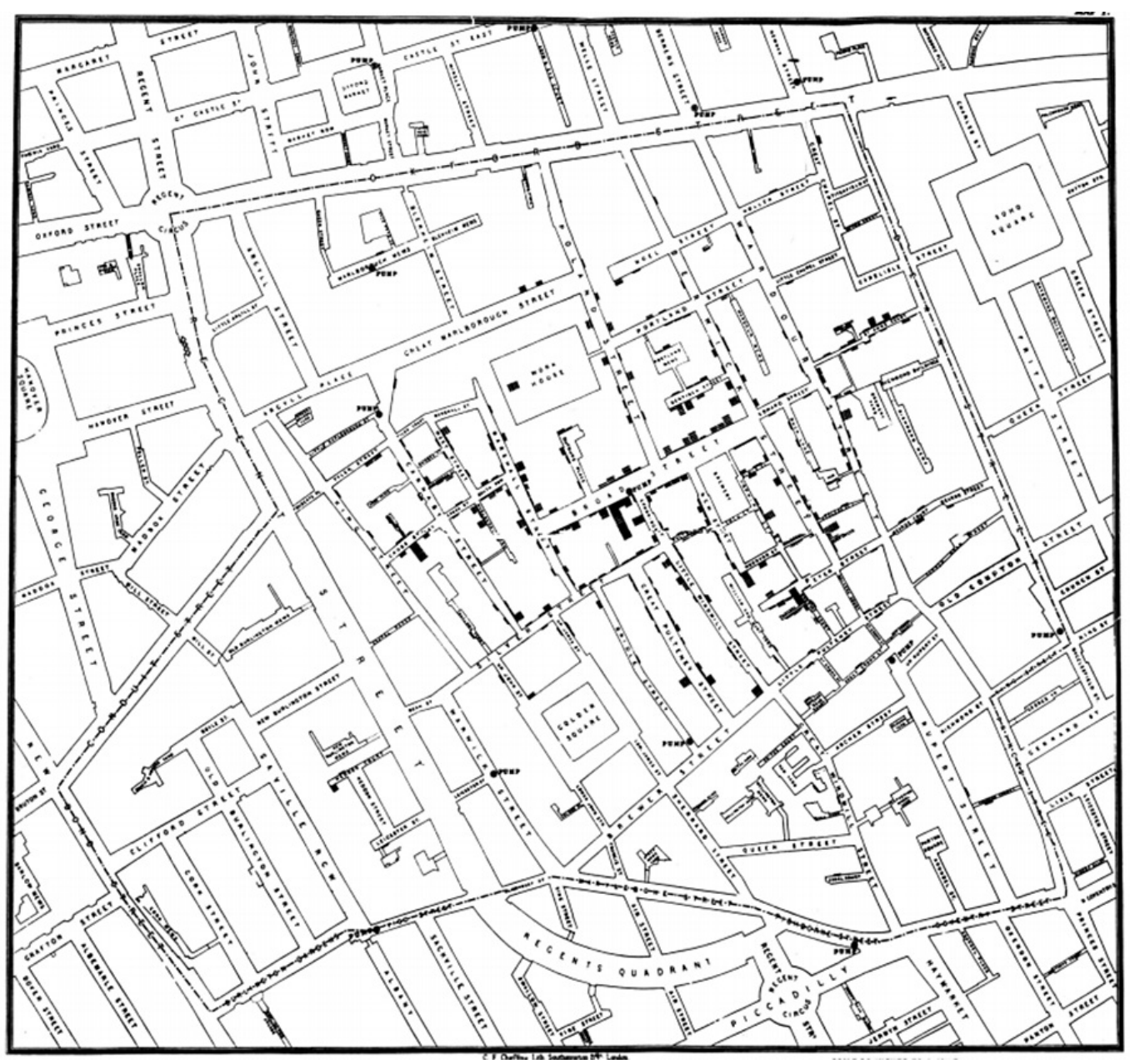

\section{FIGURE 1: Cholera mapping}

By charting of deaths in places of residence (black marks), John Snow revealed that cholera clustered around the Broad Street pump in the Barbican, London, 1854. Source: Snow, J. (Rights expired). 


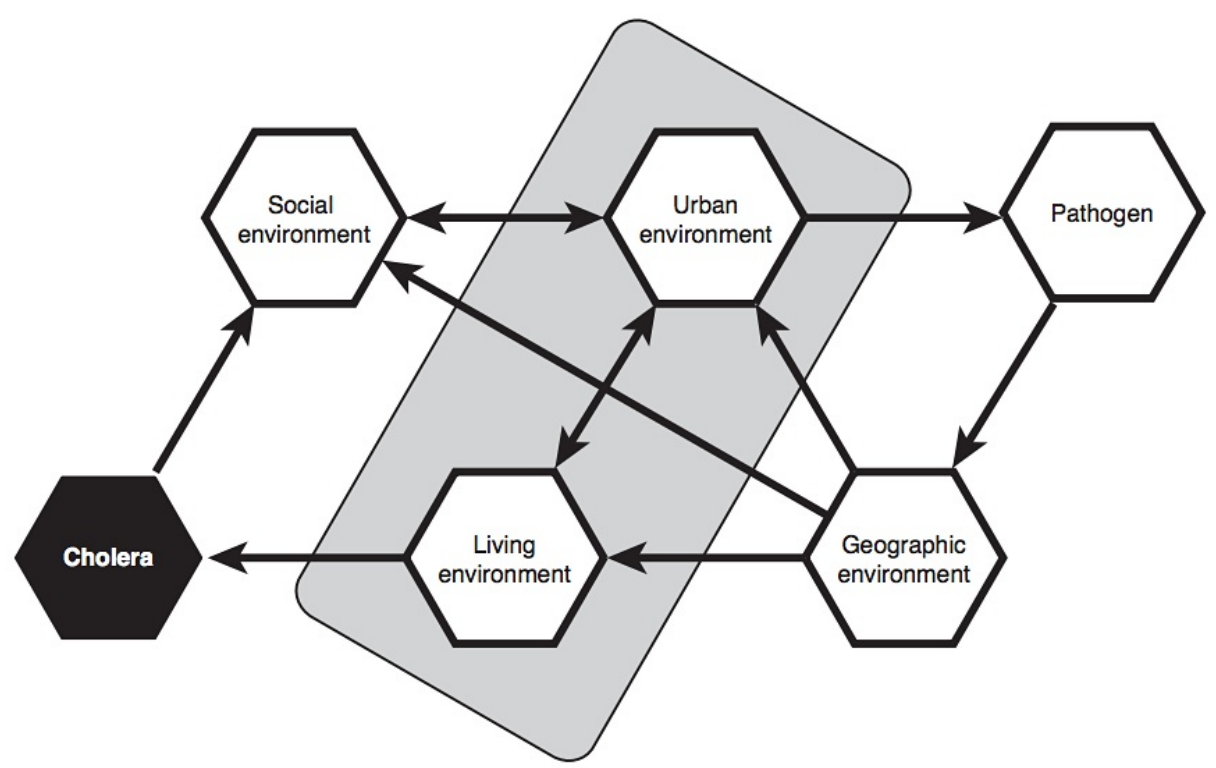

\section{FIGURE 2: Trace diagram}

The epidemiology of the Broad St Pump charted the urban (in this case, the public infrastructure; the streets and the pump itself) and the living environment (the quarters of the deceased) in order to trace the effect of an unknown pathogen to a known illness (cholera). The mapped areas are marked here in grey, and the finding - the pathogen in black. The interplay of other factors (background) was very significant; the social and geographic environments, in particular, but knowledge of the contaminated water table and the way the social environment clustered around it was only made clear after the cause of the cholera was identified. Nearly a century later, similar methods are still being used to identify similar findings, albeit with better controls for drift. However, even with new methodological approaches, tighter definitions (insanity has been restrictively redefined as schizophrenia), and different cohorts, studies are still identifying lack of sunlight and social dysfunction as 'risk factors'. The problem is that effect sizes are universally small and therefore cannot positively identify causality. The multifactor hypothesis attempts to explain how small effect 'risk factors' will compound to cause the illness. [3] In some instances, factors don't only add together, they seem to multiply.

\section{Review}

Nearly a century later, similar methods are still being used to identify similar findings, albeit with better controls for drift. However, even with new methodological approaches, tighter definitions (insanity has been restrictively redefined as schizophrenia), and different cohorts, studies are still identifying lack of sunlight and social dysfunction as 'risk factors'. The problem is that effect sizes are universally small and therefore cannot positively identify causality. The multifactor hypothesis attempts to explain how small effect 'risk factors' will compound to cause the illness [3]. In some instances, factors don't only add together, they seem to multiply.

A well-documented example is a case of multiple factors compounding together is ecogenetic (genetic x ecological factors) [4]. This involves the catechol-O-methyltransferase (COMT) gene and exposure to cannabis in adolescence (age being another factor which is at once social, biological, and environmental). The COMT gene is expressed in one of three functional states: Met/Met, Val/Met and Val/Val. Whichever functional state a person inherits makes very little difference in the likelihood of developing schizophreniform disorder as an adult. When isolated, cannabis use also represents a relatively small risk factor for adult schizophreniform disorders (OR 1.13, CI 95\%). However, individuals with the Val/Val polymorphism were found to have a high risk factor (OR 10.9, CI 95\%) if they were a cannabis user during adolescence. This 
contrasts to the Val/Met variation (OR 2.5, CI 95\%) and to Met/Met individuals who showed no additional likelihood of developing the disorder (OR 1.1, CI 95\%), a risk factor that was statistically insignificantly lower than the factor of cannabis alone [5].

As the authors of the COMT x cannabis x age study (cited above) made explicit in their findings, statistical analyses that are used to identify causal relationships are at risk of cum hoc ergo propter hoc (correlation or false cause being taken as cause) fallacies being made in the interpretation of data. To protect against epiphenomenal confounding, there is an increasing obligation to link data with biological mechanisms that are known to be active in schizophrenia; this often involves atypical morphologies of dopamine or glutamate neurons. Scientists often go further, with animal studies that inevitably produce peculiar behaviour, which is declared to be an animal equivalent of schizophrenia. The fact that there are dozens of such models, and each quite different, should be alarming [6-7]. This allows for post-hoc strategies, where the animal model of schizophrenia is developed - apparently to prove the hypothesis. These strategies don't disprove the hypothesis, but neither do they prove them. An example is the developmental Vitamin D Deficiency Schizophrenia animal model, which was generated apparently to justify the Vitamin D deficiency model of diagnosable schizophrenia [8-9]. This model manifests "abnormal motor responses to psychomimetic agents...and cognitive deficits" [10]. Attempts to reverse engineer schizophrenia in animals run the risk of complicating data with comparison fallacies; the diagnosis of human schizophrenia is subtle and great care has to be taken so that it is not confused with other human psychoses [11], much less with induced psychoses of other mammals - even if they are primates. Furthermore, these strategies do not protect against other fallacies, such as information biases. Epidemiological mapping always contains such biases, because inclusion criteria must be chosen prior to a study being undertaken. These inclusions will be based on what is already known or suspected, and on what is readily measurable. This means that larger factors may well be ignored because they haven't yet been considered, are difficult to control, to identify, justify, or are not prone to clustering and therefore to study.

The influence of 'urbanicity' in the aetiology of schizophrenia is widely and consistently reported. When tested against a null hypothesis and when controlled for other known factors (such as racial and genetic factors), meta-analyses of the urban environment as place of birth increases the odds of developing schizophrenia can be traced to $28-34.3 \%$ of all cases [12]. This does not have to be taken as evidence that the urban environment has an effect on schizophrenia (this assumption would be fallacious), but it is definitely a robust enough finding to dismiss the automatic scepticism that abounds when this possibility is addressed. It is possible to hypothesize that the urban environment has no effect on schizophrenia, per se - but rather that it exerts a negative salutogenic influence - in other words, it fails to protect against the forces that cause schizophrenia.

Whilst ecological effects may be able to multiply a genetic predisposition, there's no reason to reject the possibility that all other factors may also be subject to greater weighting. This is speculated to occur in a social context, for instance, where risk factors for schizophrenia, such as low IQ, poor hearing or immigration status, are multiplied by social discrimination [13]. Note that this evidence is weak; in fact, a recent meta-analysis appears to demonstrate the opposite. A high IQ prior to the prodrome correlates strongly to the development of the syndrome - 93\% of 1007 subjects had good/fair high-school performance [14].

There are other areas where multi-factor compounding takes place, which may be obscure because of information biases. Of these (on occasion when it has been studied), the urban landscape has consistently and evenly been shown to have a dose-dependent, raised incidence of schizophrenia [15]. Like genetics, urbanicity appears to be a causal factor, because urban birth and upbringing precedes the development of the disorder [15]. 


\section{Cureus}

The effects of many urban factors have been noted to be significant; social cohesion [13, 16], the quality of urban fabric [17], urban density [17], the ethnic makeup of the area [18], the geographical location [19], etc. However, like genetic factors on their own, each factor has a relatively small effect size, which appears to multiply collectively in the urban milieu.

The urban environment is a melting pot for many external factors, implying that multi-factor relationships take place in the urban milieu. The living environment (home), however, provides the principal filter for the ecological effects of urbanicity and the factors that urbanicity draw together: society, civic services, poverty, atmosphere, geography, and collective identity. The living environment is also, and possibly more importantly, the melting pot for internal factors because it is the primary milieu for self-development and for behaviour, especially during childhood or when social networks are depleted. Factors like these are very difficult to measure directly, but they have already been implicated in the expression of schizophrenia [20]. It remains to be seen whether 'urbanicity' is a proxy for the built environment, whether the etiological influence of the urban setting may in fact be the mediation of the architectures of home or work, and of other places where day-to-day life takes place.

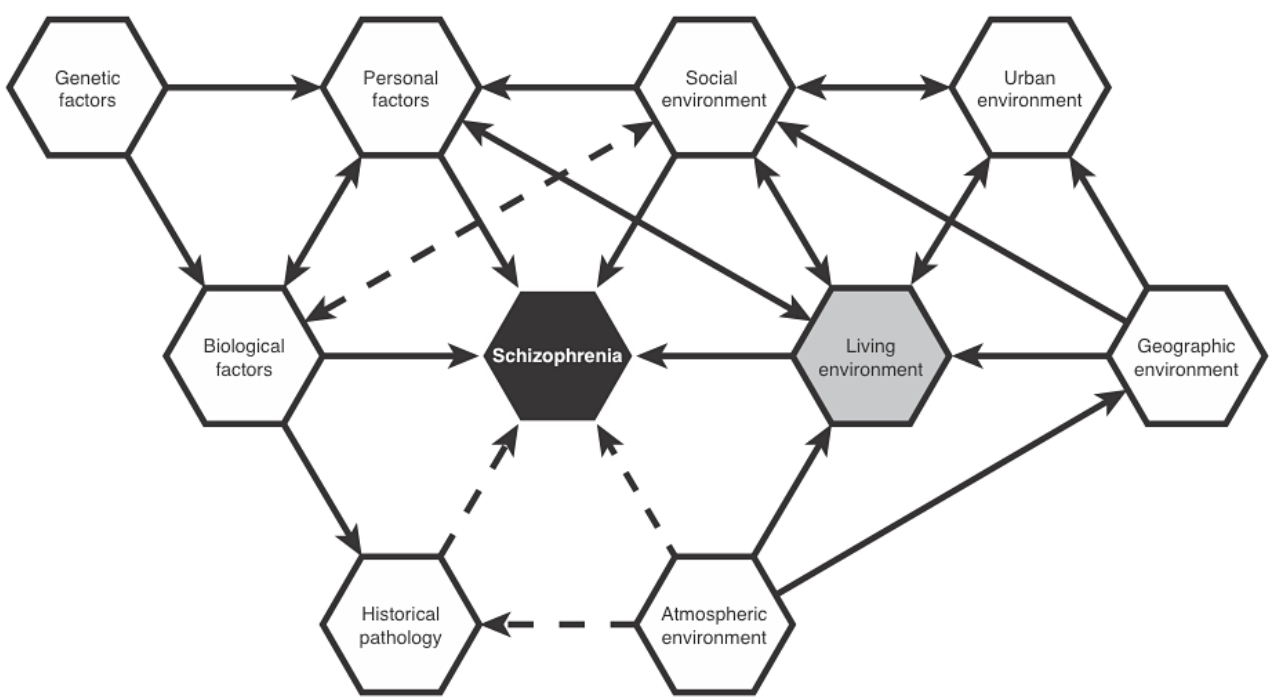

\section{FIGURE 3: Trace diagram}

The multiple factors of schizophrenia epidemiology appear to come together in schizophrenia itself rather than in any identifiable epidemiologically distinct milieu. Having said this, of all the 'pathways,' the living environment (grey) is the epicentre of all the most important identifiable 'factors': the social environment, the urban environment and other epidemiologically significant factors, such as geography. The high implication of the urban environment in the incidence of schizophrenia (28-34\%) may be in how closely it relates to the living environment (and not vice versa). 


\section{Cureus}

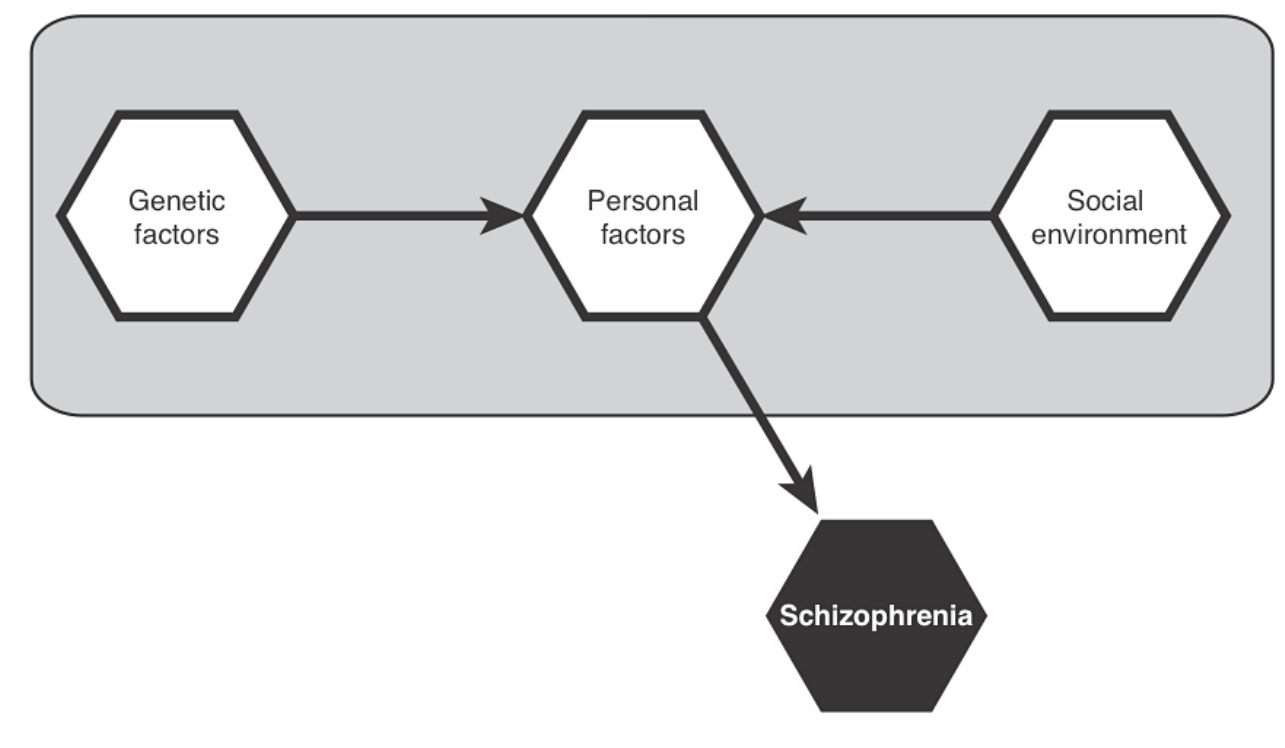

FIGURE 4: Trace diagram

Factors that are mapped for the social defeat hypothesis [13] pinpoint a single psychological mechanism (social defeat). The authors claim that this is the product of the compounding of genetic factors (such as racial appearance and hearing impediments), social factors (competition), and personal factors (use of illicit drugs and low IQ [10]). 


\section{Cureus}

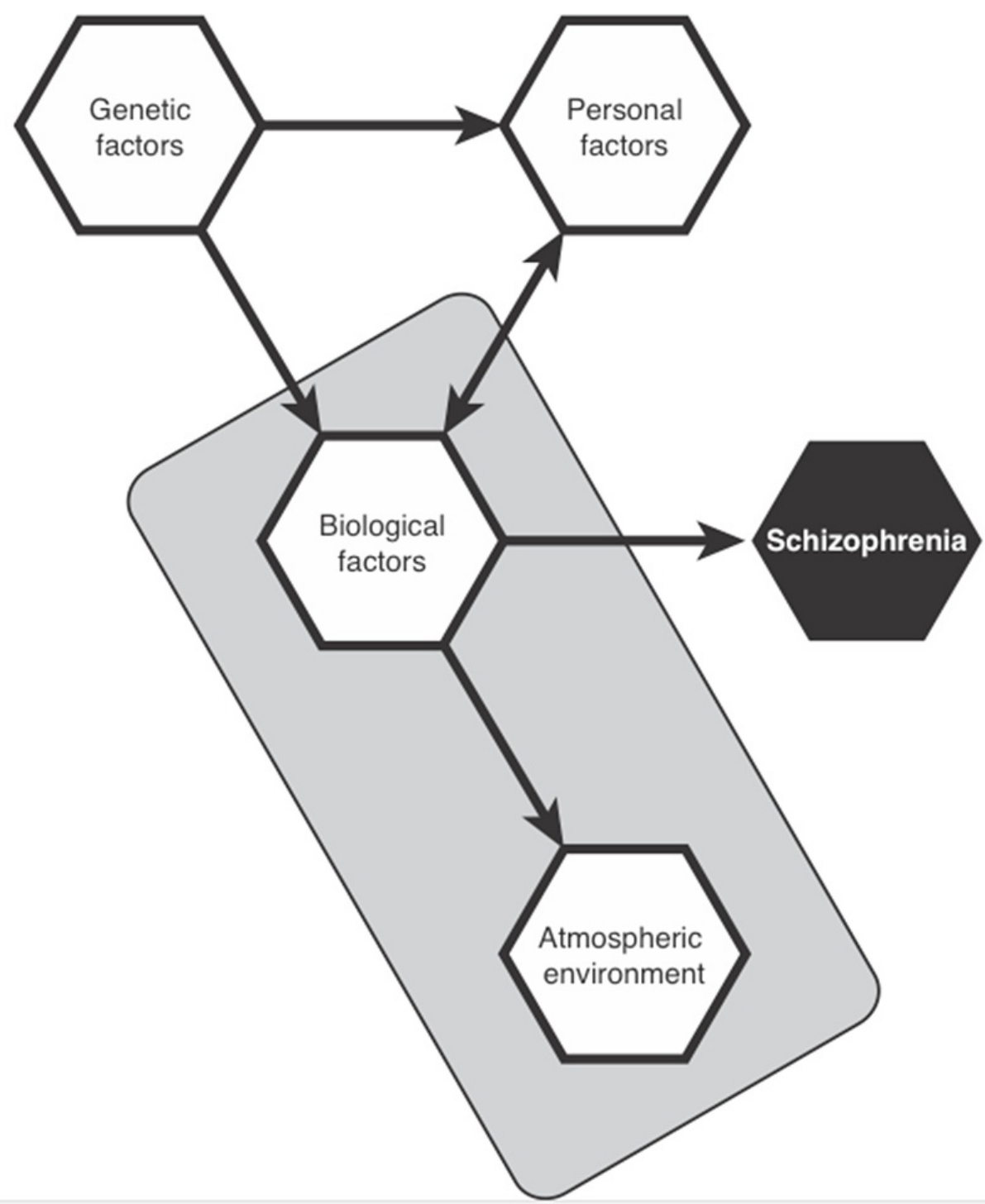

\section{FIGURE 5: Trace diagram}

Factors that are mapped for the vitamin D hypothesis pinpoint a biological mechanism (vitamin $\mathrm{D}$ deficiency due to long northern European winters). They also take account of some genetics (UV reflectivity of skin) and personal factors (dietary vitamin D).

The vitamin D hypothesis reduces many environmental variables to the supply of vitamin D at various critical points of a person's life: specifically to availability of sunlight, the most universal supply of ultra violet-B spectrum of light (UVB), which is the precursor for vitamin D synthesis. For this reason, theorists predicted that people born in the northern winters, where and when there is virtually no sun, would make them susceptible to schizophrenia later in life. The hypothesis also suggests that the high incidence of schizophrenia among immigrants from Africa and the Caribbean is because the skin colour of these immigrants is dark and therefore reflects more UVB. In addition, in the cold European climates, the reduction of UVB is compounded by the need to wear heavier clothing, which blocks UVB entirely. Other factors that affect vitamin D supply are dietary; that is, consumption of fish (which is naturally high in dietary vitamin D) but also of vitamin D supplements [21].

There is no doubt; these associations tend to concur with the vitamin D deficiency hypothesis 
once outliers are excluded. Despite the linear graphs that Kinney, et al. [21] present, the relationships are nonlinear and are marked by exceptions. The exceedingly high schizophrenia clusters in North West Ireland, where the risks at (17.4/1000) are among the highest in the world, appears to be one such exception [22-23]. This population is presumably largely fairskinned but has a strong fishing industry [24]. It is speculated that exceptions like these must be complicated by increased genetic risks of an unidentified nature (i.e., not skin colour, genes) [19]. Other secondary elaborations that are used to round up the outliers (frequently by some of the same authors) is exposure to the feline parasite, toxoplasma gondi, [21, 25-26] and poverty, which is linked to an inability to provide youngsters with supplements [21]. Genetics, infections, and parasites are just a few of many factors that also appear to create a predisposition for schizophrenia that have no clear relationships with vitamin D. Poverty may have a lot to do with vitamin D deficiency, but surely this is very speculative.

Architectural factors are no less indistinct. There are many architectural factors that may affect people and predispose them to schizophrenia - these should be looked at as seriously as fish consumption, and perhaps more seriously; after all, the entire schizophrenia research community is shooting in the dark when it comes to schizophrenia aetiology, and all factors that show high incidence rates should be the focus of attention. What about the quality and tenure of housing? Workplace and facilities for leisure? The direction buildings face? Do they collect sunlight or look away? Is the air quality good or is it ionised or polluted? Are surfaces hard or soft? Are living places comfortable or not? There are other ecological factors, too: Are these environments prone to fungal or bacterial growth? Are pets, vermin or other animals present? And the quality of interior light: does the spectrum include UV? Is it bright enough to trigger cones, or do people get by only using rod-vision? With all of these other factors, add the effects of varying amounts of daylight, of temperature and humidity, and the question of how clusters occur become very difficult to resolve.

In order to clarify whether vitamin D deficiency is epiphenomenal or causal, Eyles, et al. [10] undertook a study of vitamin D-deprived rats. The researchers took a population of pregnant rats and removed vitamin $\mathrm{D}$ from their diets and the diets of their pups. The researchers were careful that the lighting was balanced: (light for 12 hours/day, dark for 12 hours), but with no ultraviolet spectrum to prevent natural synthesis of vitamin D. Other rats were kept in similar conditions, but were fed with supplements [10]. The results of this study were impressive, with the rats developing certain key morphologies that compare to schizophrenia: these include a sensitization to glutamate antagonists, minor distortions of brain shape, increased lateral ventricle volumes, reduced differentiation, diminished expression of neurotropic factors, and peculiar behaviours that are speculated to be 'schizophrenic.' The assumption that induced rodent psychosis is equivalent to schizophrenia, however, is difficult to support. Even human schizophrenia is not a correlate of human psychosis and findings, such as ventricle size, are not valid diagnostic criteria [11]. Certainly they are common correlates and may even be directly due to vitamin D deficiency, but they, like so many other correlations, are tendencies that are not ubiquitous [27]. Psychosis is but one set of defining symptoms, and one that is excluded if there is no marked decrease in social function [11]. The rats that were subject to this study had no noticeable social dysfunction [10] and were therefore definitively not schizophrenic. The study is once again suggestive, but proves only that the target has somehow been missed.

The complexity of data can be read a number of ways; either that the aetiology of schizophrenia is itself complex with multiple compounding causal factors, [3-4, 28-29] or perhaps that the variation is a product of being close to the target but still a little way off. Surely, John Snow also noticed more and more illness and death as he approached Carnaby Street (Figure 1)? Compare Figures 3, 4 with the bigger picture presented in Figure 2. High, but not absolute, correlations are expected from the social environment and from biological factors, but unless they show a 1:1 correlation, variation will not reflect cause as such, but correlations, epiphenomenal and comorbid effects. If this is the case, the aetiology of schizophrenia may still be parsimonious 
and singular but somewhere that hasn't been studied properly.

The physical built environment is sufficiently complex to be such an illusive target. Just because it cannot be as easily unravelled and analysed as the human genome and it can't be put into a lab and studied under microscopes doesn't mean it's not the bull's-eye we're all looking for.

The effect the physical environment has on human psychology is often overlooked as a causal factor. The physical environment has a powerful influence on the social milieu and also on other possible aetiological factors, including civic, geographical, demographic, personal, and other ecological influences. In fact, the physical milieu has an influence on nearly every factor that has ever been targeted in the search for the aetiology of schizophrenia so far - the primary exception being genetics. This idea has been publically scoffed at in the past [30], and to this day, the hypothesis receives little scientific attention. The reasons for this are twofold: Firstly, it is difficult to control environmental conditions for human subjects and therefore difficult to study. Secondly, environmental aetiologies reach outside of the traditional domain of psychiatry and into architecture, non-clinical psychology, anthropology, and sociology.

Evidence of the etiological effect of the environment is in its infancy, but already preliminary findings are no less coherent than those of alternative hypotheses - and are possibly better.

The statistical variables raised by the vitamin D case can be explained by the physical environment: In this model, low levels of vitamin D are an indicator of reduced exposure to the sun because of being indoors. Even in a brightly lit milieu, light through glass is filtered of most UV.

Data gathered in various boroughs of South London shows extreme variation in the incidence of schizophrenia. From one borough to another contiguous one, incidence may increase by several times [31]. Even accounting for ethnicity and other demographic data, the increased odds ratio remains extreme [16, 31-33]. This data, hitherto unexplained, might mean that schizophrenia is the product of lack of general stimulation or environmental poverty: a childhood lifestyle characterized by housing estates and run-down neighbourhoods (ubiquitous in the AESOP sample), with overworked and stressed parents and too much babysitting by the TV. But in spite of this variation, environmental poverty, like schizophrenia, can be found even in the most salubrious homes and well-manicured suburbs, and in countries where sunshine, and therefore vitamin D, is bountiful. Could a vitamin D deficiency in early childhood indicate a lack of stimulation? This would mean that the aetiology for schizophrenia is psychological and possibly sociological, but not biological, at least in the developmental stage.

\section{Conclusions}

Epidemiological studies of schizophrenia find that financial poverty and schizophrenia have a close relationship, but like vitamin $\mathrm{D}$, the correlation reflects an impressive tendency, but still not a 1:1 relationship. The studies find the children of migrants have particularly high [34] incidence of schizophrenia in later life. The data of McGrath, Eyles, et al. [9] suggests that this may be due to maternal and neonatal Vitamin D deficiency in the 'new country' [10]. Whilst this is a very worthy argument, the same data may mean that kids are brought up with little more than a TV for company and stimulation, while the parents try to get ahead in their new life.

Schizophrenia is strongly associated with poor lifestyle, but the question about whether poor lifestyle is the product of schizophrenia or predisposes people to it dates right back to Faris and Dunham [1].

McGrath asks, "Is it time to trial Vitamin D supplements to prevent schizophrenia?" [35]. To this 
question, the answer must surely be yes, but this doesn't have to be at the expense of taking care that the environments in which we rear our children are rich and rewarding. Another question is no less important - is it time to look at the built environment as an aetiological factor for schizophrenia?

\section{Additional Information \\ Disclosures}

Conflicts of interest: In compliance with the ICMJE uniform disclosure form, all authors declare the following: Payment/services info: All authors have declared that no financial support was received from any organization for the submitted work. Financial relationships: All authors have declared that they have no financial relationships at present or within the previous three years with any organizations that might have an interest in the submitted work. Other relationships: All authors have declared that there are no other relationships or activities that could appear to have influenced the submitted work.

\section{Acknowledgements}

This work was supported by the Schizophrenia Research Institute, utilizing infrastructure funding from NSW Department of Health.

\section{References}

1. Faris REL, Dunham HW: Mental disorders in urban areas: An ecological study of schizophrenia and other psychoses.. University of Chicago Press, Chicago, IL; 1939.

2. Freeman HL, Alpert M: Prevalence of schizophrenia in urban population. The British Journal of Psychiatry. 1986, 149:603-11.

3. Van Os J, Kenis G, Rutten BPF: The environment and schizophrenia.. Nature. 2010, 468:20312.

4. Van Os J, Rutten BP, Poulton R: Gene-Environment Interactions in Schizophrenia: Review of Epidemiological Findings and Future Directions. Schizophr Bull. 2008, 34:1066-82.

5. Caspi A, Moffitt T, Cannon M, McClay J, Murray R, Harrington H, et al.: Moderation of the effect of adolescent-onset cannabis use on adult psychosis by a functional polymorphism in the catechol-O-methyltransferase gene: longitudinal evidence of a gene X environment interaction. Biol Psychiatry. 2005, 57:1117-27.

6. Marcotte ER, Pearson DM, Srivastava LK: Animal models of schizophrenia: a critical review . J Psychiatry Neurosci. 2001, 26:395.

7. Kilts CD: The changing roles and targets for animal models of schizophrenia . Biol Psychiatry. 2001, 50:845-55.

8. McGrath JJ, Saari K, Hakko H, Jokelainen J, Jones PB, Järvelin MR, et al.: Vitamin D supplementation during the first year of life and risk of schizophrenia: a Finnish birth cohort study. Schizophr Res. 2004, 67:237-45.

9. McGrath JJ, Eyles DW, Pedersen CB, Anderson C, Ko P, Burne TH, et al.: Neonatal Vitamin D Status and Risk of Schizophrenia: a population based case-control study. Arch Gen Psychiatry. 2010, 67:889-94.

10. Eyles DW, Feron F, Cui X, Kesby JP, Harms LH, Ko P, et al.: Developmental vitamin D deficiency causes abnormal brain development. Psychoneuroendocrinology. 2009, 34:S247S57.

11. American Psychiatric Association: Diagnostic and Statistical Manual of Mental Disorders (DSM): American Psychiatric Association. Washington D.C; 1994.

12. Kelly BD, O'Callaghan E, Waddington JL, Feeney L, Browne S, Scully PJ, et al.: Schizophrenia and the city: A review of literature and prospective study of psychosis and urbanicity in Ireland. Schizophr Res. 2010, 116:75-89.

13. Selten JP, Cantor-Graae E: Hypothesis: Social Defeat is a risk factor for schizophrenia?. The British Journal of Psychiatry.. 2007, 191:s9-s12.

14. McGrath JA, Avramopoulos D, Lasseter VK, Wolyniec PS, Fallin MD, Liang K-Y, et al.: 
Familiality of Novel Factorial Dimensions of Schizophrenia. Arch Gen Psychiatry. 2009, 66:591-600.

15. Krabbendam L, van Os J: Schizophrenia and urbanicity: a major environmental influence conditional on genetic risk. Schizophr Bull. 2005, 31:795.

16. Kirkbride JB, Boydell J, Ploubidis GB, Morgan C, Dazzan P, McKenzie K, et al.: Testing the association between the incidence of schizophrenia and social capital in an urban area.

Psychol Med. 2008, 38:1083-94.

17. Curtis S: Geographical Perspectives on Psychiatric Disorder. The Impact of the Environment on Psychiatric Disorder. Freeman HL, Stanstead S (ed): Routeledge, London, New York; 2008. 52-79.

18. Coid JW, Kirkbride JB, Barker D, Cowden F, Stamps R, Yang M, et al.: Raised Incidence Rates of All Psychoses Among Migrant Groups; Findings From The East London First Episode Psychosis Study. Arch Gen Psychiatry. 2008, 65:1250-59.

19. Torrey EF, Mortensen PB, Pedersen CB, Wohlfahrt J, Melbye M: Risk factors and confounders in the geographical clustering of schizophrenia. Schizophr Res. 2001, 49:295-99.

20. Golembiewski J: All common psychotic symptoms can be explained by the theory of ecological perception. Med Hypotheses. 2012, 78:7-10.

21. Kinney DK, Teixeira P, Hsu D, Napoleon SC, Crowley DJ, Miller A, et al.: Relation of schizophrenia prevalence to latitude, climate, fish consumption, infant mortality, and skin color: a role for prenatal vitamin d deficiency and infections?. Schizophr Bull. 2009, 35:58295.

22. Freeman D: Schizophrenia and City of Residence. Brit J Psychiat. 1994, 164:39-50.

23. Torrey EF: Prevalence studies in schizophrenia. Br J Psychiat. 1987, 150:598-608.

24. The Irish Department of Agriculture Fisheries and Food: Ireland's response to the Commission's Green Paper on the Reform of the Common Fisheries Policy. ( Dublin 2009). www.fishingnet.ie.

25. Torrey EF, Bartko JJ, Yolken RH: Toxoplasma Gondii and Other Risk Factors for Schizophrenia: An Update. Schizophr Bull. 2012, sbs043.

26. Yolken RH, Dickerson FB, Fuller Torrey E: Toxoplasma and schizophrenia. Parasite Immunol. 2009, 31:706-15.

27. Rosa PGP, Schaufelberger MS, Uchida RR, Duran FLS, Lappin JM, Menezes PR, et al.: Lateral ventricle differences between first-episode schizophrenia and first-episode psychotic bipolar disorder: A population-based morphometric MRI study. World J Biol Psychiat. 2010, 11:87387.

28. Muller N, Dursun SM: Schizophrenia genes, epigenetics and psychoneuroimmunology therapeutics: all make sense now?. J Psychopharmacol. 2011, 25(6):713-4.

10.1177/0269881110364268

29. Rutten BPF, Mill J: Epigenetic Mediation of Environmental Influences in Major Psychotic Disorders. Schizophr Bull. 2009, 35:1045-56.

30. Mc Grath JJ: Environmental risk factors in schizophrenia: Does developmental vitamin D deficiency play a role?. ASC Molecules to Mind Ann Mtg. Sydney; presentation September 22, 11:00am; 2010.

31. Kirkbride JB, Fearon P, Morgan C, Dazzan P, Morgan K, Murray R, et al.: Neighbourhood variation in the incidence of psychotic disorders in Southeast London. Soc Psychiatry Psychiatr Epidemiol. 2007, 42:438-45.

32. Kirkbride JB, Fearon P, Morgan C, Dazzan P, Morgan K, Tarrant J, et al.: Heterogeneity in Incidence Rates of Schizophrenia and Other Psychotic Syndromes Findings From the 3-Center AESOP Study. Arch Gen Psychiat. 2006, 63:250-58.

33. Kirkbride JB, Morgan C, Fearon P, Dazzan P, Murray R, Jones PB: Neighbourhood-level effects on psychoses: re-examining the role of context. Psychol Med. 2007, 37:1413-25.

34. Beebe LH, Tian L, Morris N, Goodwin A, Allen SS, Kuldau J: Effects of exercise on mental and physical health parameters of persons with schizophrenia. Issues Ment Health Nurs. 2005, 26:661-76.

35. McGrath JJ: Is it time to trial vitamin D supplements for the prevention of schizophrenia? . Acta Psychiatr Scand. 2010, 121:321-24. 